\title{
Promoting Responsible Business Practices: A Case of Chambers of Commerce
}

\author{
Udo Braendle \\ American University in Dubai \\ ubraendle@aud.edu \\ Amir Hossein Rabdari \\ Tarbiat Modares University / \\ Corporate Governance and Responsibility Development Center, Tehran \\ Hassan Farajzadeb Dehkordi \\ University of Raja
}

\begin{abstract}
Employer organizations and business associations are the advocates of private organizations' interests. They also provide a platform for private enterprises to tap into synergetic and collaborative opportunities. Chambers of commerce, in particular, as well-organized establishments in the business environment are in a unique position to guide and assist organizations to thrive and stay competitive. To this end, recently, chambers of commerce have embarked on fostering responsible business practices among their members. The raison d'être behind this movement and the types of action taken have been largely neglected by the academic research. This study examines a number of leading chambers of commerce and business associations from both developed and developing countries in an attempt to shed light on the current responsible business practices in these organizations.
\end{abstract}

Key words: Corporate social responsibility, chamber of commerce, responsible business, sustainability. 


\author{
Abbreviation: \\ ACCI: Australian Chamber of Commerce and Industry \\ BCC: British Chambers of Commerce \\ BDA: Bundesvereinigung der Deutschen Arbeitgeberverbände \\ BDI: Bundesverband der Deutschen Industrie \\ CII: Confederation of Indian Industry \\ CSR: Corporate Social Responsibility \\ DCCI: Dubai's Chamber of Commerce \\ DIHK: Deutscher Industrie- und Handelskammertag \\ FPCCI: Federation of Chambers of Commerce and Industry \\ USCC: US Chamber of Commerce \\ ZDH: Zentralverband des Deutschen Handwerks
}

\title{
1. Introduction
}

Chambers of commerce and business associations are not only representatives of private organizations' interests, but are catalysts for economic and business development across economies. Chambers of commerce, in particular, guide and assist organizations to thrive and stay competitive. As part of this mission, chambers of commerce foster responsible business practices among their members. The reasons they do this and the types of actions taken have been largely neglected by academic research. The purpose of this study is to examine a number of leading chambers of commerce and business associations from both developed and developing countries in an attempt to shed light on the current responsible business practices in these organizations. Based on a framework (organizational structure, covered aspects, and types of practices), we compare the responsible business initiatives of a sample of business associations in developing and developed countries.

Firstly, we provide some theoretical background on chambers of commerce and business associations, CSR, and responsible business practices. Then, we go on to give the profiles of the organizations reviewed. Next, we present the results and discussion. And finally, we conclude by alluding to the crucial role played by business associations, chambers of commerce, and CSR associations in encouraging responsible business practices among their members, establishing it as competitive force in the business environment, and increasing public awareness of the issue of business responsibility towards society. 


\section{Theoretical Background}

\subsection{Chambers of Commerce and Business Associations}

Chambers of commerce and business associations are recognized across economies as catalysts for economic and business development. In most countries they are the leading partners in economic initiatives in the private sector. They have the advantage to government that they are democratically elected from the business community, have transparent governance that offers legitimacy, and are locally-rooted (Bennet, 2011). Chambers of commerce have developed as a result of the historical evolution and the constraints of the socio-economic environment (Maennig et alii, 2015). Since they are intermediary service organizations between government and business, they have emerged and developed with the market economy (Brockmann and Lacho, 2015). The more mature and developed the market economy is, and the more developed the market economy system is, the greater need there is for chambers of commerce to play an intermediary role (Huang, 2005).

Both, chambers of commerce and business associations are membership organizations engaged in promoting the business interest of their members . The structure, role and effectiveness of business associations depend on the legal framework of the country and state (or province) they operate in. The services they provide can be rudimentary at one end of the spectrum, providing only networking opportunities, or they can be influential full service organizations if it comes to the other end of the spectrum (Bennet, 2011). The various activities of chambers of commerce are intended to establish favorable conditions for businesses, including influencing economic and social actors for creating and seizing new business opportunities, working with rule-making organizations that affect international trade and foreign investments, preventing potential conflicts with stakeholders and minimizing political risk, and actively engaging the media and other public arenas for safeguarding image and reputation of business companies (Saner et alii, 2000; Noel and Luckett, 2014).

Both, chambers of commerce and business associations are voluntary and non-profit organisations. They perform by similar functions, with the following differences: 
Table 1: Comparison between Business Associations and Chambers of Commerce

\begin{tabular}{|l|l|l|}
\hline Criteria & Business Associations... & Chambers of Commerce... \\
\hline $\begin{array}{l}\text { Nature of } \\
\text { member-firms }\end{array}$ & Are essentially competitors & $\begin{array}{l}\text { Member-firms are not } \\
\text { competitors }\end{array}$ \\
\hline Scope & $\begin{array}{l}\text { Consist of business firms } \\
\text { operating in the same industry. }\end{array}$ & $\begin{array}{l}\text { Include companies operating } \\
\text { in different fields of business } \\
\text { activity } \text { wider in scope }\end{array}$ \\
\hline Representation & $\begin{array}{l}\text { Protect and promote the } \\
\text { interests of a particular industry. }\end{array}$ & $\begin{array}{l}\text { Represent the interests of } \\
\text { business community in general }\end{array}$ \\
\hline Structure & $\begin{array}{l}\text { Contain business firms } \\
\text { operating in different regions }\end{array}$ & $\begin{array}{l}\text { Are often organised on regional } \\
\text { basis }\end{array}$ \\
\hline
\end{tabular}

Trade associations take many forms including chambers of commerce, employer organizations, and other types of business networks and associations. Chambers of commerce is arguably the most common form of private business association in the world with the objective of protecting and furthering the interests of businesses.

Local business Associations are distinct from industry based organizations in that they offer specific services to their members rather than collective benefits (Bennett 1996). They are recognized as providing their members international, national and local promotion opportunities; a register of premises; general advice; advice for startups; and a business directory (Bennett and Krebs 1994). By virtue of building and maintaining social relationships and networking, local business associations may be able to create relational and social capital and therefore an innovative milieu (Maennig and Ölschläger 2011). The organizational forms of chambers of commerce vary across countries. We differ between three different chambers of commerce governance modes in the world: a) the government-led mode, b) the market-driven mode and c) the cooperation with government mode.

As for the government-led chambers of commerce (Germany as a representative), they are established on the basis of governmental leadership and funding. The establishment and participation is compulsory in this model. Sources of income mainly come from governmental funding, except for membership dues and paid services (Maennig et alii, 2015). Another characteristic is that the government gives some guidance and supervision to chamber of commerce affairs. There is a principle of exclusivity, which means that only one chamber of commerce of one type is allowed to be set up in one area. Areas at different levels 
set up chambers of commerce at different levels, and the higher-level chambers of commerce do not have leadership power over subordinate levels.

The governmental control of chambers of commerce in countries operating under the Anglo-American legal system (market-driven) is fairly relaxed. Chambers of commerce are legal persons established on the basis of private law. Chambers of commerce are typically autonomous where companies can voluntarily choose to join a certain chamber of commerce. The chamber is funded by membership fees and paid services. The role of the government generally is not to interfere with the internal affairs of chambers of commerce and generally does not adopt specific laws to regulate chambers of commerce.

Chambers of commerce constructed according to the cooperation with government mode are insofar different as they have been established after learning and absorbing the advantages and successful experiences of the other two modes. Some of these chambers of commerce adopt a mandatory membership system, funding comes from memberships and paid services plus some government funding. These chambers have the autonomy to deal with internal affairs under government guidance.

\subsection{Corporate Social Responsibility}

Although the concept of sustainability was already discussed in the earliest days of industrialization, it is since the 1960s that diverse stakeholders, including governments, media and the broader public are increasingly concerned with organizations' commitment to general governance standards, environmental and social issues as well as community involvement. Primarily been understood as environmental sustainability (Crane and Matten, 2007) the concept was developed further to embrace environmental, social, and economic sustainability. This development has to be seen in the context of the growing importance of multinational companies in this time. This is also inherent in the notion of the triple bottom line, which entails the thinking that people, planet and profit are inextricably linked with each other. Organizations can create long-term value by striving to expand the life span of societies, ecosystems, and economies (Elkington, 2010).

Hence, the United Nations convened the World Commission on Environment and Development in 1983, also known as Brundtland Commission, to address widespread concern about growing socioeconomic inequalities, the depletion of natural resources, and environmental destruction. The Brundtland Commission espoused the view that the answer to the aforementioned global challenges was sustainable development, i.e. "development that meets the needs of the present 
without compromising the ability of future generations to meet their own needs" (UN 1987, p. 37). Although the concepts of sustainability and corporate social responsibility (CSR) have gained a significant position in the general management literature, there is still uncertainty about how to adequately define them (Dahlsrud 2008).

At the corporate level, sustainable development is often communicated through the concept of CSR (Elkington, 2010) and it connects corporate operations and activities to various aspects of sustainable development (Waddock $\&$ Graves, 1997). CSR and sustainability are intertwined concepts that have taken many forms and have been defined in various ways based on the time and/ or the context of the discussion (Rahdari \& Rostamy, 2015).

\subsection{Responsible Business Practicesः Developed vs. Developing Countries}

Even though the term sustainability emerged from Western countries, hereby especially the U.S., the inherent core values of sustainability are not new to developing countries. The debate on CSR is gaining stronger roots in developed economies, with companies exploring better ways of disclosing sustainability news to their stakeholders. This is so, not least because these companies are aware of the effect of their activities on the people, communities and the environment (Frederick et alii, 1992). Where developing countries have been covered in the literature, this usually involved the activities of US or European companies there, thus targeting multinational companies rather than local ones (e.g. Husted and Allen, 2006).

This being said, since some years now, we have seen a raise of interest in responsible business practices in developing countries, coupled with some growth in the number of articles and (book) chapters written in this field (Jamali and Neville, 2011).Kühn et alii (2015), for example, provide an extensive list of research on CSR in developing countries. There are strong indications by theoretical and empirical works that the understanding and implementation of CSR varies across differing institutional contexts (Matten and Moon, 2008). An area that has received relatively less attention within this broad research agenda pertains to the role of small and medium enterprises (SMEs) in responsible business practices in the developing world (Noel and Luckett, 2014). SMEs have been recognized to contribute significantly to job creation and poverty alleviation in developing countries, given their labor-intensive production processes and significant employment growth rates (Jamali et alii, 2015). Chambers of commerce from developed and developing countries alike can play a role in filling this gap and shall be described in the next section. 


\section{Organizational Profiles}

A short introduction on each of the examined organizations would provide a backdrop for the analysis presented later in the study.

\subsection{The Confederation of Indian Industry (CII)}

$\mathrm{CII}$ is the India's premier business association and has over 7200 members, from the private as well as public sectors, including SMEs and MNCs, and an indirect membership of over 100,000 enterprises from around 242 national and regional industry bodies. It is a non-government, not-for-profit, industry-led and industry-managed organization, playing a proactive role in India's development process and was founded in 1895. Extending its agenda beyond business, CII assists the industry to identify and execute corporate citizenship programs. Partnerships with civil society organizations carry forward corporate initiatives for integrated and inclusive development across diverse domains including affirmative action, healthcare, education, livelihood, diversity management, skill development, empowerment of women, and water, to name a few.

\subsection{A Network of German Business Associations}

The CSR in Germany initiative was developed by the Federal Ministry of Labour and Social Affairs (BMAS) and is supported by BDA, BDI, DIHK, and ZDH. It is in the CSR portal of the German business community. Therefore, in lieu of reviewing of major business association in Germany, it behooves to review a network of German Business Associations including DIHK, BDI, BDA, ZDH, and B.A.U.M.

\subsubsection{Deutscher Industrie- und Handelskammertag (DIHK)}

As the umbrella organization of 80 German Chambers of Industry and Commerce, DIHK protects the interests of German business against policymakers in the German political world and the European institutions. The DIHK represents general business interests on the basis of a broad crosssection of business people. Approximately, 3.6 million commercial businesses are statutory members of Chambers. This means that the Chambers organization is independent of individual interests and carries a particular weight vis-à-vis policymaking bodies. 


\subsubsection{Bundesverband der Deutschen Industrie (BDI)}

$\mathrm{BDI}$ is the leading organization of German industry and industrial services representing 37 sectoral confederations and more than 100,000 companies accounting for more than eight million employees. It is the voice of German industry against policymaking institutions at national, European and international level.

\subsubsection{Bundesvereinigung der Deutschen Arbeitgeberverbände (BDA)}

BDA is the leading social policy organization in the German business community. It represents the interests of small, medium-sized and large companies from all sectors on all issues relating to social and pay policy in relation to policymakers, trade unions and public opinion. It is the voice of business and offers a comprehensive range of services to its members. BDA protects the interests of one million businesses accounting for employing twenty million workers and which are linked to BDA through their voluntary membership in over 6,500 employer federations.

\subsubsection{Zentralverband des Deutschen Handwerks ( $\mathrm{ZDH})$}

ZDH brings together 53 chambers of skilled crafts, 36 central confederations of skilled crafts as well as important business and academic skilled crafts institutions in Germany. ZDH is a forum for developing harmonized positions on all fundamental issues linked to crafts policy. It represents the overall interests of skilled crafts vis-à-vis German parliament, German government and other central German authorities, the EU and international organizations.

\subsection{Dubai's Chamber of Commerce and Industry (DCCI)}

Established in 1965, the DCCI is a private non-profit organization, whose stated purpose is to support the business community in Dubai and promote Dubai as an international business hub. The DCCI established the Centre for Responsible Business in 2004 to support and promote Corporate Social Responsibility, Sustainability, and Corporate Governance good practices. The Centre's objective is to enable the Dubai business community to assume greater responsibility in meeting social and environmental needs. The CRB also promotes the Emirate of Dubai as the region's gateway for global commerce by offering its global business partners an environment of transparency and rule of law. Services of the DCCI include, but are not limited to, legal services, arbitration and mediation; 
organizing training programs as well as trade fairs and economic forums, credit rating services and providing access to updated research and numerous reports.

\subsection{Australian Chamber of Commerce and Industry (ACCI)}

Australia is characterized by some large corporations that control a large proportion of the market and their powerful industry based associations on the one hand and a large number of disorganized small and micro businesses with smaller local-based business associations on the other hand (Bennett 1998). As a member based organization it combines the brand strength of the international, national and local chamber of commerce movement with the capability of Australia's specialist business associations. State and Territory Chambers of Commerce federate as the Australian Chamber of Commerce and Industry (ACCI,) and these are joined by industry associations which form the ACCI national member network. That network represents in excess of 300,000 private enterprises engaging over three million employees, most of them being SMEs. Representation and policy development on (inter)national matters is part of ACCI's mission. That includes the multiple traditions of business advocacy, from trade and commerce, to economics and tax, to employment, labor and social policy. Beyond the global, a tier of regional and bilateral associations to Australia's north, west and east complete ACCI's international network.

\subsection{US Chamber of Commerce (USCC)}

The United States Chamber of Commerce (USCC) is a business-oriented American lobbying group. It is not an agency of the United States government. USCC's mission is to strengthen the competitiveness of the U.S. economy. It describes itself as the world's largest business federation representing more than three million businesses and organizations of every size, sector, and region. The US Chamber is different from local and state chambers of commerce located in many cities, towns and states nationwide. Local and state chambers of commerce are founded and operated independently, though they may be affiliated with the US Chamber of Commerce. As of 2015, the Chamber had a worldwide network of 116 American Chamber of Commerce affiliates located in 106 countries. 


\subsection{Pakistan's Federation of Chambers of Commerce and Industry (FPCCI)}

Pakistan's FPCCI, established in 1950, has advocated and voiced the collective opinion, concern, and aspiration of the private sector and has offered helpful advice and solid assistance to the Pakistani government in its efforts to promote exports, encourage foreign investment and stimulate economic activity in the country. FPCCI represents 44 Chambers of Commerce and Industry, 9 Women's Chambers of Commerce \& Industry, 5 Chambers of Small Traders, 103 all Pakistan Associations, representing Industry, Trade and Service sectors. FPCCI has established Standing Committees on CSR to promote responsible business practices. It had 14 committees under its wing in 2014. The Standing Committee on CSR is built on the purpose of increasing productivity and competitiveness of local businesses by redefining their stakeholders' boundaries: implementing strategies to ensure the confidence of not only shareholders, but all elements involved and affected by an entity. This has triggered the aspiration of the FPCCI Standing Committee on CSR to integrate CSR into core business practices and as a part of organizational mission and vision - in written policy, action and spirit.

\subsection{British Chambers of Commerce (BCC)}

The British Chambers of Commerce (BCC) is a business network with accredited chambers in region of the UK, and in markets around the world. The BCC falls within the tmarket-driven mode of chambers described above. The chief functions therefore are: (1) representation and lobbying; and (2) service provision including training; (3) community support; (4) group marketing; and (5) social/peer support aspects (see Grant, 1993 and Bennett, 2011). Analyses have demonstrated that access to services networks are the most important motives for Chamber membership, although they are strongly interlinked with other benefits, such as representation, perceived to derive from chambers (Bennett, 2011). In a voluntary system, each Chamber's management responds to local needs and demand from its members. Through the Association of British Chambers of Commerce (ABCC) - a voluntary body to which all medium and large British Chambers belong - core service are offered: representation; business information and international trade; In addition, many Chambers are involved with extensive business training and a significant number have business counselling and other services (Bennett, 1996). 


\section{Findings and Discussions}

In the previous section, an overview of the profiles of reviewed organizations was presented. The examined organizations were either a business association or a chamber of commerce. These organizations, by playing the role of a catalyzer, have started fostering responsible business practices in their business ecosystems. The crux of this descriptive study is to provide an overview of responsible business practices being promoted in these organizations alongside the governance structures supporting these practices. To conduct a comparative analysis among these business associations in relation to their responsible business initiatives it is necessary to develop a common framework. The framework in Figure 1 encompasses three main categories viz. organizational structure, covered aspects, and types of practices. The framework was inductively derived from surveying the above described and several other chambers of commerce / business associations.

Figure 1 - framework for reviewing responsible business practices among business associations

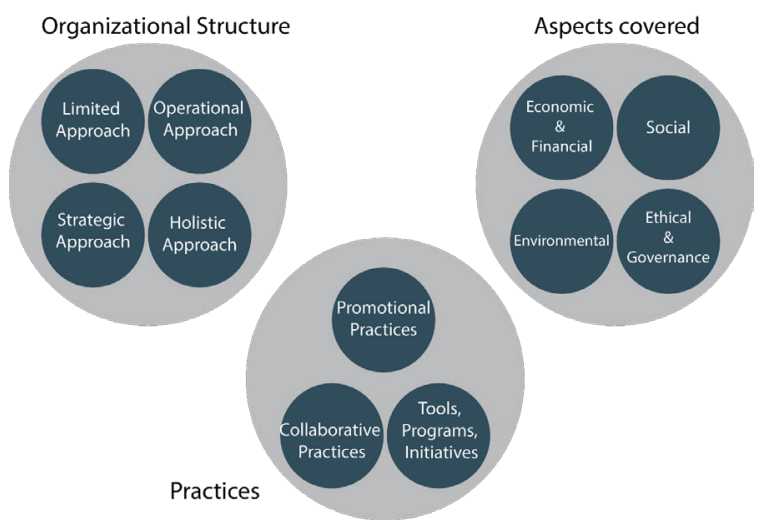

After reviewing each organization using the framework, the organizational structures in charge of promoting responsible business practices and two main analyses were conducted to examine the covered aspects in the responsible business program of the organizations including economic, environmental, ethical, social, and governance as well as the types of practices that are being promoted in the examined organizations namely promotional, collaborative, and tools, programs, $\&$ initiatives. In the next section, heterogeneous organizational governance structures are elucidated upon. Next, the results of examination on covered aspects and types of practices are presented. 


\subsection{Organizational (Governance) Structure}

The approaches and organizational forms taken to promote responsible business practices in chambers of commerce are diverse. The chambers demonstrated heterogeneous governance structures for managing their responsible business strategies that can be categorized into four approaches: Limited Approach, Operational Approach, Strategic Approach, and Holistic Approach.

The organizations adopting the first two approaches - which applies to most chambers of commerce in developing countries - are still in nascent state of developing CSR. Chambers with ad hoc responsible business practices made no alterations in their organizational structure and defined responsible business practices alongside their normal activities with the objective of improving the image of the chamber. They took a Limited Approach to CSR and responsible business practices. Chambers that adopted Operational Approach established committees and temporary organizational structure to improve responsible business among their members (e.g. CII and Pakistan's FPCCI). Figure 2 demonstrates the relative expected relationship between organizational governance structure and the level of integration of responsible business practices.

Figure 2, responsible business integration and organizational governance structure

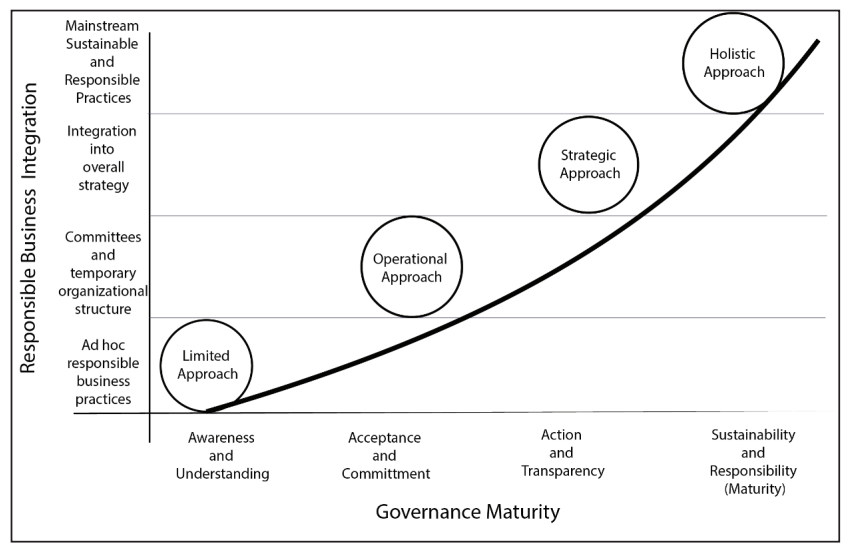

Some chambers adopted the Strategic Approach to CSR in employer organizations. These organizations perceived a business case for CSR, meaning it would pay off, and embedded it in their overall strategy on the premise that it helps their members and themselves to gain more competitive advantage. Therefore, they therefore established long-term organizational structures such as center(s) 
for promoting responsible business practices among their members as well as embracing it themselves in their activities, which should help especially SMEs. This type of organizational structure is prevalent among employer organizations in Laissez-faire economies (e.g. Dubai and US Chamber of Commerce). Finally, there is Holistic Approach. Chambers of commerce/business associations that embraced CSR and responsible business practices not as a byproduct of their normal activities but as a mainstream approach (e.g. German Chambers of Commerce). The organizations adopting these two approaches are more advanced in promoting CSR for all organizational structures. Having said that, it worth noting that these organizational structures are only in relation to the integration of responsible business practices and how they are being fostered by these organizations. They differ from their overall organizational structures.

\subsection{Covered Aspects and Practices}

\subsubsection{Promotional Practices}

Promotional practices for fostering responsible business practices are usually the first steps taken to raise awareness and understanding over responsibility of business towards society. The common practices include, but not limited to, research including articles, reports, etc., books and guidelines, and events (workshops, webinars, conferences, seminars). The following figure 3 shows the results of Promotional Practices and Covered Aspects intersection for the examined organizations. On a scoring scale from 0 to 1,0 refers to low or nonexistence, 0.5 to medium and 1 to high.

Figure 3. Promotional Practices - Covered Aspects

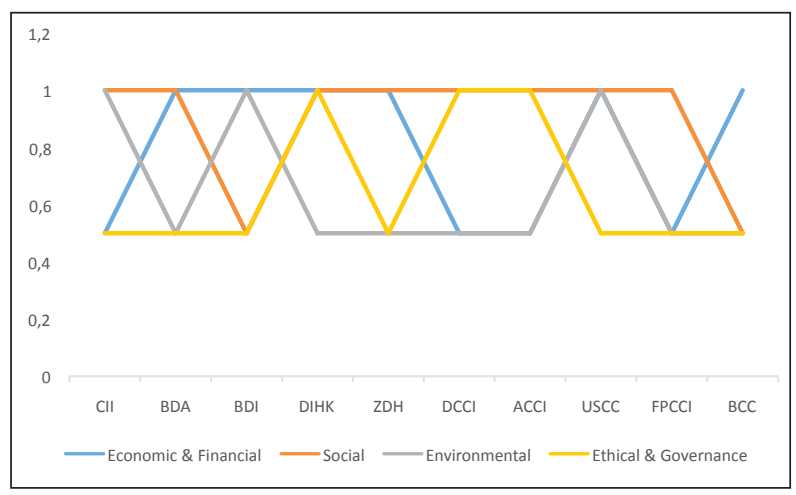




\subsubsection{Collaborative Practices}

Collaborative practices for fostering responsible business practices are among the middle-to-high maturity practices that are prevalent mostly in developed countries especially in Europe. Cross-sectional partnership, community engagements, and inter-jurisdictional collaborations are the part and parcel of these practices. The following figure 4 shows the results of Collaborative Practices and Covered Aspects intersection for the examined organizations.

\section{Figure 4. Collaborative Practices - Covered Aspects}

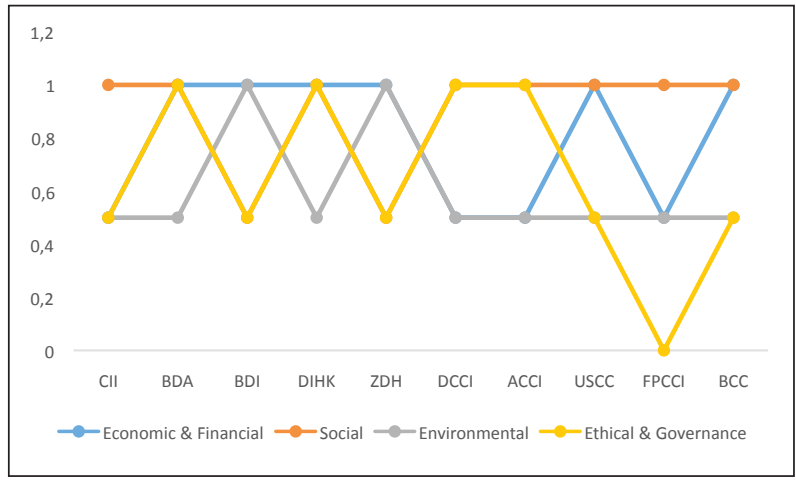

\subsubsection{Tools, Programs, and Initiatives}

Tools, programs, and initiatives are the vehicles of change in fostering responsible business practices. These vehicles are used to solve economic, social, and environmental problem and to create a business case for CSR to further its implementation through enlightened self-interest. The following figure 5 shows the results of Tools, Programs, Initiatives and Covered Aspects intersection for the examined organizations.

\section{Figure 5. Tools, Programs, Initiatives - Covered Aspects}

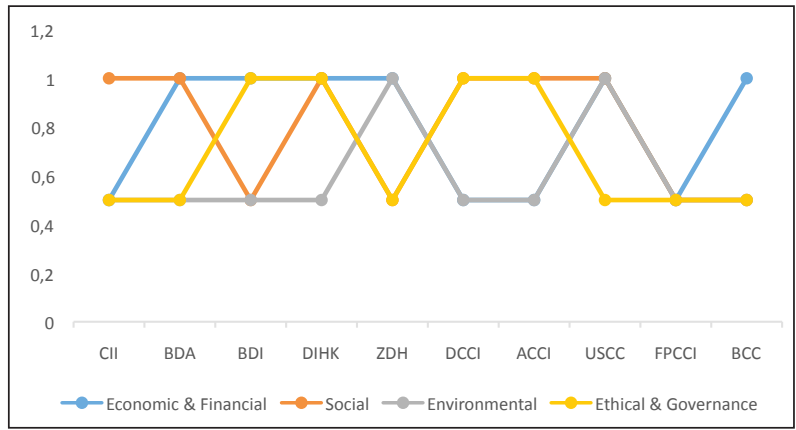


The final results (following figure 6) showed that DIHK scored the highest among all chambers across all three dimensions. Then USCC and BDA ranked second and third. In general, German business associations performed the best due to their comprehensive responsible business practices.

Figure 6. The overall score of Covered Aspects

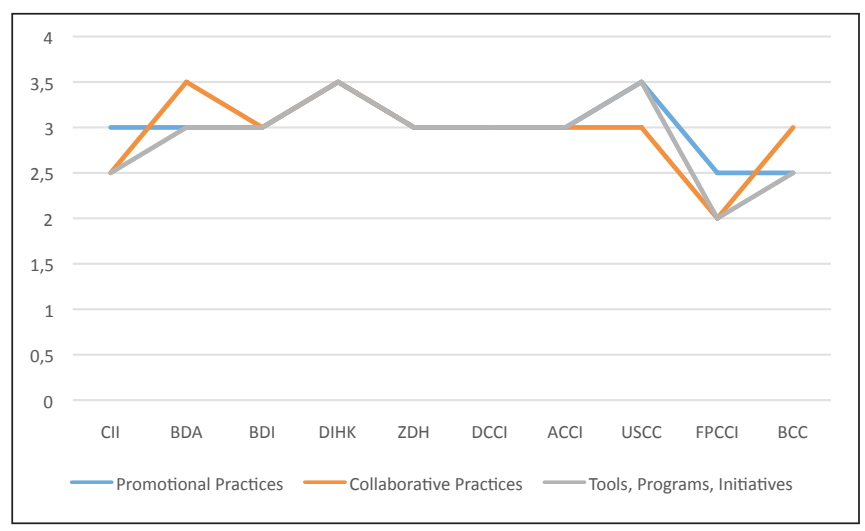

The study also showed that as business associations and chambers of commerce further their responsible business practices, they adopt a more holistic governance approach. Moreover, the more advanced responsible business practices they have, the more comprehensive are their covered aspects (economic \& financial, social, environmental, ethical \& governance). Finally, business associations with intensive collaborative programs (German business associations) tend to perform well on promotional and tools $\&$ initiative aspects showing that comprehensive collaborative programs are only observable in business associations with advanced responsible business practices.

\section{Conclusion}

In many countries chambers of commerce and business associations are the leading private sector partners in economic initiatives. Fostering responsible business practices among their members has recently been put on top of the agenda.

Having been understood primarily as environmental sustainability the concept of responsible business practices or CSR was developed further and now embraces environmental, social, and economic sustainability. This stance is also inherent in the notion of the triple bottom line, which entails the thinking that people, planet and profit are inextricably linked with each other and that 
organizations can create long-term value by striving to expand the life span of societies, ecosystems, and economies (Elkington 2010).

For a sample of 10 chambers of commerce covering developing and developed countries, we have used a framework encompassing three main categories (organizational structure, covered aspects, and types of practices). The organizational structures in charge of promoting responsible business practices and two main analyses were conducted to examine the covered aspects in the responsible business program of the 10 organizations including economic, environmental, ethical, social, and governance as well as the types of practices that are being promoted in the examined organizations. Although the approaches and organizational forms taken to promote CSR in chambers of commerce are diverse - developing countries' chambers are using a limited - and operational approach in the organizational structure compared to a strategic and holistic approach in developed countries - the gap between developed and developing countries is smaller than assumed. The organizations in developing countries are still in nascent state of developing CSR. They defined responsible business practices alongside their normal activities with the objective of improving the image of the chamber. In developed countries, organizations perceived a business case for CSR and embedded it in their overall strategy on the premise that it helps their members and themselves to gain more competitive advantage. Especially the German Chambers of commerce/business associations embraced CSR and responsible business practices not as a byproduct of their normal activities but as a mainstream approach.

We understand that the number of chambers of commerce and business associations that satisfied the required common denominators of this study were limited mostly due to the unavailability of public disclosure on responsible business practices and CSR activities of these organizations. Further, the number of organizations studied may not provide solid grounds for the generalization of the results to all chambers of commerce and business association. We believe that future studies can evaluate responsible business practices in specific countries further. 


\section{References:}

Bennett, R. J. (1996) “"The Logic of Local Business Associations: An Analysis of Voluntary Chambers of Commerce". Journal of Public Policy, 15(3): 251279.

Bennett, R. J. (1998). "Business Associations And Their Potential To Contribute To Economic Development: Re-exploring An Interface Between The State And Market". Environment and Planning, 30(8): 1367-1387.

Bennett R. J. (2011). Local Business Voice: The History of Chambers of Commerce in Britain, Ireland, and Revolutionary America 1760-2011. Oxford: Oxford University Press.

Bennett, R. J., and Krebs, G. (1994). "Local Economic Development Partnerships: An Analysis of Policy Networks in EC-LDA Local Development Strategies". Regional Studies, 28(2): 119-140.

Brockmann, E. N. and Lacho, K. J. (2015)."Benefits of chamber of commerce membership: Large vs. small population centers". The Entrepreneurial Executive, 20:31-38.

Crane, A., and Matten, D. (2007). Business ethics: Managing corporate citizenship and sustainability in the age of globalization ( $2^{\text {nd }}$ ed.). Oxford: Oxford University Press.

Dahlsrud, A. (2008). "How Corporate Social Responsibility is defined: An analysis of 37 definitions". Corporate Social Responsibility and Environmental Mangement, 5: 1-13.

Elkington, J. (2010). "Corporate sustainability”. In W. Visser; D. Matten, M. Pohl, and N. Tolnurst (eds.), The $A$ to $Z$ of corporate social responsibility (1st ed.), Chichester: Wiley Publishing: 114-119.

Grant, W. (1993). Business and Politics in Britain (2nd ed.), London: Macmillan. Husted, B. and Allen, D. (2006). "Corporate Social Responsibility in the Multinational Enterprise: Strategic and Institutional Approaches". Journal of International Business Studies, 37(6): 838-849.

Jamali, D., and Neville, B. (2011). “Convergence versus divergence in CSR in developing countries: An embedded multi-layered institutional lens". Journal of Business Ethics, 102: 599-621.

Jamali, D.; Lund-Thomsen, P; Jeppesen, S. (2015). "SMEs and CSR in Developing Countries". Business E Society: 1-12.

Kühn, A.-L.; Stiglbauer, M.; Fifka, M. (2015)."Contents and Determinants of Corporate Social Responsibility Website Reporting in Sub-Saharan Africa - A Seven-Country Study". Business and Society, online first. 
Maennig, W., and Ölschläger, M. (2011). "Innovative Milieux and Regional Competitiveness: The Role of Associations and Chambers of Commerce and Industry in Germany". Regional Studies, 45(4): 441-452.

Maennig, W*; Ölschläger, M., and Schmidt-Trenz, H.-J. (2015). "Organisations and regional innovative capability: the case of the chambers of commerce and industry in Germany, Environment and Planning C". Government and Policy, 33: 811-827.

Matten, D., \& Moon, J. (2008). "Implicit" and "explicit” CSR: A conceptual framework for a comparative understanding of corporate social responsibility". Academy of Management Review, 33: 404-424.

Noel, M., and Lucketт, M. (2014). "The benefits, satisfaction, and perceived value of small business membership in a chamber of commerce". International Journal of Nonprofit and Voluntary Sector Marketing, 19: 27-39.

Rahdari, A.H., and Rostamy, A.A. (2015), "Designing a general set of sustainability indicators at the corporate level". Journal of Cleaner Production, 108: 757-771.

Saner, R.; L. Yiu, and M. Sondergaard (2000). "Business Diplomacy Management: A Core Competency for Global Companies". Academy of Management Executive, 14(1): 80-92.

United Nations (1987). Report of the world commission on environment and development, our common future, New York: United Nations.

Waddock, S.A., and Graves, S.B. (1997)."The Corporate Social Performance - Financial Performance Link". Strategic Management Journal, 18 (4): 303 319. 